\title{
Evaluation of the Liver Enzyme (AST, ALT \& ALP) Levels of Adult HIV Patients on HAART in UPTH
}

\author{
Chinwe F. Anyanwu ${ }^{1}$, Eric O. Aigbogun Jr. ${ }^{2^{*}}$ and Tosin O. Joseph ${ }^{1}$ \\ ${ }^{1}$ Department of Pharmacology, Faculty of Basic Clinical Sciences, University of Port Harcourt, Nigeria. \\ ${ }^{2}$ Department of Anatomy, Faculty of Medical Sciences, Kampala International University,
}

Western Campus, Uganda.

Authors' contributions

This work was carried out in collaboration among all authors. Authors CFA and EOAJ conceptualized the research and formulated the topic, co-designed the study, co-drafted the ethical clearance proposal. Author EOAJ analyzed the data and author TOJ managed the literature searches, harmonized sectional write-ups and provided the final manuscript. All authors participated in data collection, read, reviewed and approved the final manuscript.

Article Information
DOI: 10.9734/ARRB/2020/v35i330198
Editor(s):
(1) Dr. David E. Martin, Martin Pharma Consulting, LLC, Shawnee, OK, USA.
Reviewers:
(1) Abayomi Afe, Texila American University, Guyana.
(2) Idorenyin Umoh, University of Uyo, Nigeria.
Complete Peer review History: $\underline{\text { http://www.sdiarticle4.com/review-history/51211 }}$

Original Research Article

Received 10 July 2019

Accepted 17 September 2019

Published 02 May 2020

\begin{abstract}
This study evaluated the liver enzyme levels of HIV-infected adult patients on highly active antiretroviral treatment (HAART) for not less than 1 year. The study was designed as a randomised cross-sectional study that evaluated the differences in the aspartate aminotransferase [AST], alanine transaminase [ALT] and alkaline phosphatase [ALP] of 129 (46 males and 83 females) HIVinfected adult patients. Before the study, ethical clearance (Ref: UPH/CEREMAD/REC/19) was obtained from the University of Port Harcourt Ethics Committee. Venous blood samples were obtained and the liver enzyme levels were analysed using Clinical Chemistry Analyser (VS10) manufactured by Vitro Scient. Values were further categorised into; normal or abnormal. SPSS version 21 (IBM尺 Armonk, USA) and Graph Pad Prism (Version 8.0.2) was used to analyse the data. T-test compared the sex differences in mean, while Chi-square analysis tested the sex differences in the categorised data. From the result, the mean AST $(27.65 \pm 17.93 \mathrm{IU} / \mathrm{L})$ and ALP $(135.13 \pm 10.87 \mathrm{IU} / \mathrm{L})$ values for males were higher than females AST $(27.25 \pm 18.93 \mathrm{IU} / \mathrm{L})$ and ALP $(132.65 \pm 9.96 \mathrm{IU} / \mathrm{L})$ values, while $\mathrm{ALT}$ was higher in female $(34.66 \pm 22.29 \mathrm{IU} / \mathrm{L})$ than males $(33.75 \pm 18.14 \mathrm{IU} / \mathrm{L})$; however, the differences were not significant $(p>0.05)$. Generally, abnormal
\end{abstract}

*Corresponding author: E-mail: eric.aigbogun@kiu.ac.ug; 
AST, ALT and ALP levels were 31\%, 34\% and 82\% respectively; with no sex-associated differences ( $p>0.05$ ). $45.7 \%$ of the patients (males: 25 [54.3\%] and females: 34 [41.0\%]) had cholestatic abnormality, while $8.5 \%(5 ; 10.9 \%$ males and $6 ; 7.2 \%$ females) had hepatocellular abnormality, $18.6 \%(6 ; 13.0 \%$ of males and $18 ; 21.7 \%$ of females) and mixed abnormality (AST/ALT/ALP). In conclusion, cholestatic abnormalities were observed in more than $80 \%$ of the patients as opposed to hepatocellular abnormalities, which were less than $35 \%$. More females were associated with mixed abnormality when compared to males with independent (ALT/AST) abnormality. This study, therefore, suggests the need for a randomised case-control study to highlight the extent of deviation from normal values.

Keywords: Enzyme levels; liver; HAART; HIV-infected adults; sex.

\section{INTRODUCTION}

The term Highly Active Antiretroviral Therapy (HAART) refers to the customized combination of three or more antiretroviral agents [1] which generally consists of a combination of Nucleoside Analog Reverse Transcriptase Inhibitors (NRTI) plus a Protease Inhibitor (PI) and Non-Nucleoside Reverse Transcriptase Inhibitors (NNRTI) [2]. The increased availability of the different combinations has been identified to have the potential to increase the hepatotoxicity susceptibility. Studies by Ngala et al. [3] Wambani et al. [4] and Neukam et al. [5] suggest that prolonged use of any class of ART is implicated in hepatotoxicity that is often seen in patients undergoing drug treatment; however, the extent to which each of these drugs induces or contributes to hepatotoxicity is varied [3].

Alanine transaminase (ALT) is an enzyme found in the liver that helps convert proteins into energy for the liver cells. When the liver is damaged, ALT is released into the bloodstream and levels increase. Aspartate transaminase (AST) is an enzyme that helps metabolize amino acids, it is also normally present in blood at low levels, and an increase may indicate liver damage, disease or muscle damage. Alkaline phosphatase (ALP) is an enzyme found in the liver and bone and is important for breaking down proteins. Higherthan-normal levels of ALP may indicate liver damage or diseases, such as a blocked bile duct, or certain bone diseases [6].

There is evidence that when patients commence ART, 14-20\% will present with elevated hepatic enzymes [7] with a recent report suggesting up to $60 \%$ [8]. However, co-infection with hepatitis B or C virus $[9,10,11]$ and tuberculosis treatment [12] have also been implicated in mild hepatotoxicity. In Tanzania, efavirenz and rifampicin-based hepatotoxicity occurred in HIV patients with or without tuberculosis (TB) co-infection; however, the effects were mild, thus therapeutic modifications were not needed [13]. Whereas, in a recent case-study by Segamwenge and Bernard [14] four patients were reported to been diagnosed with acute liver failure within one month of switching to an efavirenz-based antiretroviral therapy.

It has been suggested that sex-specific thresholds be applied when investigating liver enzyme levels because women have slightly lower normal ALT levels than men [15]. This was evident in a study conducted in the U.S. that identified an ALT upper limit of $29 \mathrm{IU} / \mathrm{L}$ for men and $22 \mathrm{IU} / \mathrm{L}$ for women [16]. Additionally, in the study by $\mathrm{Wu}$ et al. [17] suggesting that liver enzymes in the aetiology of diseases, abnormal elevations may differ by sex, it is therefore imperative to investigate the role of sex in liver enzyme elevation among HIV-infected patients on HAART.

\section{MATERIALS AND METHODS}

\subsection{Research Design}

This study was designed as a "cross-sectional" part of the randomized comparative study (CEREMAD, 2016) by Anyanwu et al. [18]. The study population involved HIV-positive patients, who were on HAART for not less than 1 year and whose CD4 count was not below the critical value of 200 cells $/ \mathrm{mm}^{3}$. Personal information such as age, sex, lifestyle (alcohol and cigarette consumption), pregnancy state for the females, duration of HAART and HIV co-infections (such as pulmonary tuberculosis, hepatitis $B \& C$ ) history were obtained from their hospital folders and pre-tested questionnaires.

\subsection{Study Population}

The clinic had over twelve thousand $(12,000)$ registered HIV patients. Data for 900 HIV- 
infected patients undergoing HAART at University of Port Harcourt Teaching Hospital as at 2015 were collected. However, 392 patients were physical present for recruitment.

\subsection{Sampling Technique}

This study utilized randomised purposive sampling method.

\subsection{Eligibility and Enrolment}

1. Inclusion criteria - patients: (i) diagnosed with HIV infection and undergoing HAART; (ii) aged $>20$ years; (iii) continuing HAART ( $\geq 12$ months).

2. Exclusion criteria - patients (i) with acute HIV infection; with (ii) co-infections or severe, life-threatening complications; (iii) who were pregnant; (iv) with autoimmune diseases; (v) with incomplete data. (vi) older than 55 years of age $[19,20]$.

\subsection{Methods of Data (sample) Collection/Instrumentation}

Venous blood samples were collected and serum levels of Aspartate aminotransferase [AST], Alanine transaminase [ALT] and Alkaline phosphatase [ALP] were determined using Clinical Chemistry Analyser (VS10) manufactured by Vitro Scient. The machine utilises the operational principle guided by Beer-lambert's law (that is; the linear relationship between absorbance and concentration of an absorbing species). Normal range values were established in units per litre as follows; ALT (7 to $55 \mathrm{U} / \mathrm{L})$, AST (8 to $48 \mathrm{U} / \mathrm{L}$ ) and ALP (40 to $129 \mathrm{U} / \mathrm{L}$ ) [6].

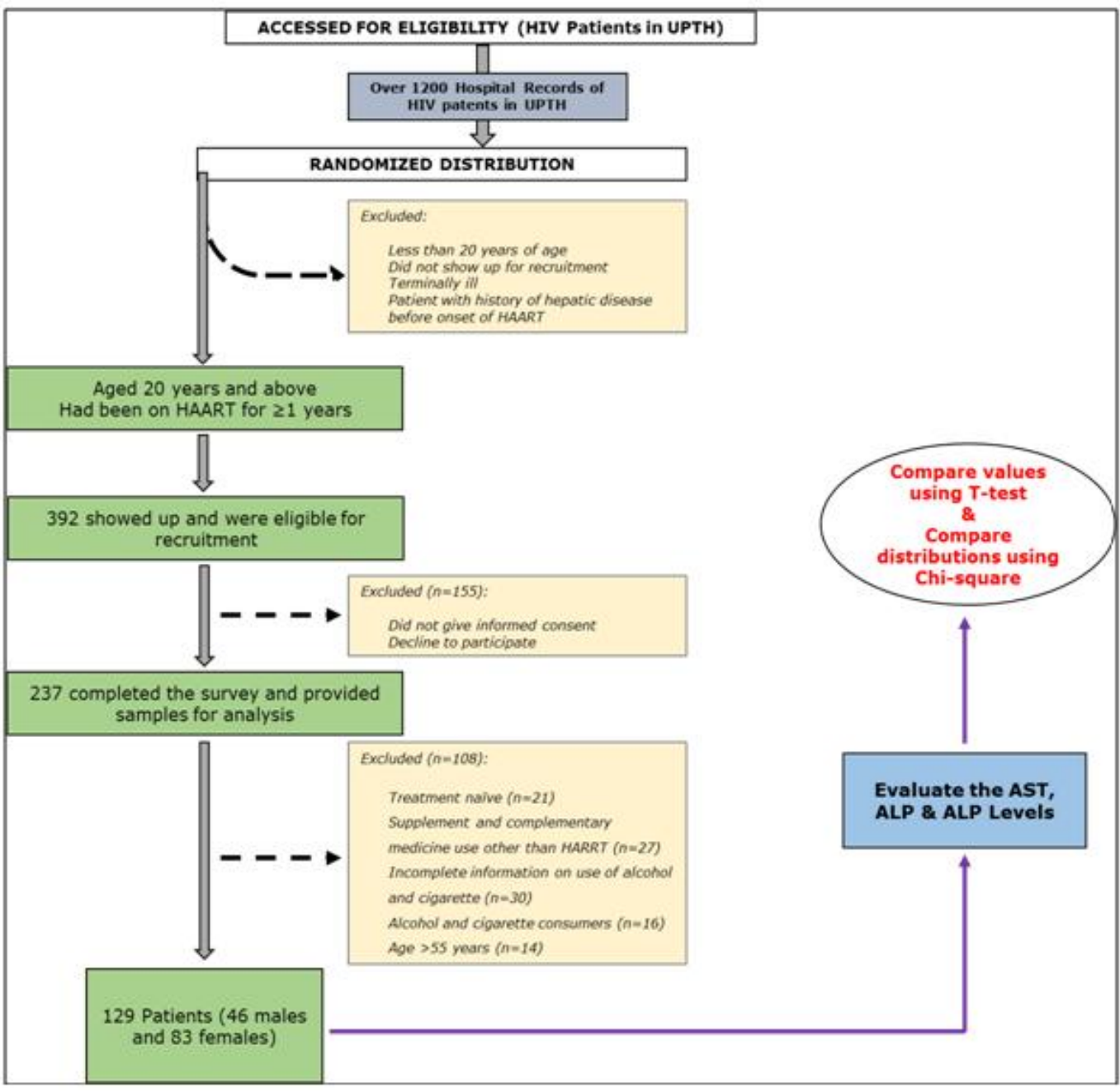

Fig. 1. Flow diagram for the research lifecycle 


\subsection{Aspartate Aminotransferase (AST)}

In a water bath for five minutes at $37^{\circ} \mathrm{C}, 500 \mu \mathrm{L}$ of reagent 1 (L-Aspartate $200 \mathrm{mmol} / \mathrm{L}$ and 2oxoglutarate $2 \mathrm{mmol} / \mathrm{L}$ ) was pipetted into a clean test tube, mixed and incubated. $100 \mu \mathrm{L}$ of the serum were added, mixed, and incubated at $37^{\circ} \mathrm{C}$ for 30 minutes. $500 \mu \mathrm{L}$ of developer $(2,4-$ dinitrophenylhydrazine) were added to the reacting tube, mixed and left to stand for 20 minutes at room temperature. $5 \mathrm{~mL}$ of $0.4 \mathrm{~N}$ $\mathrm{NaOH}$ were added to the tube and left for 5 mins at room temperature. Absorbance of the test samples were read against water blank at $500 \mathrm{~nm}$ in a light path cuvette spectrophotometerically. Results were obtained by comparing the absorbance of the test samples to a calibration values provided in the manual of the kit.

\subsection{Alanine Transaminase (ALT)}

Alanine aminotransferase (ALT) activity is measured at $546 \mathrm{~nm}$ by observing the conc. of pyruvate hydrazine formed when pyruvate reacts with 2,4-dinitrophenyl hydrazine. The rate at which the NADH is expended is proportionate to ALT catalytic activity measured at $340 \mathrm{~nm}$. Procedure is the same as AST above but only varies in the substrate. The substrate here is LAlanine and $\alpha$ - ketoglutarate.

\subsection{Alkaline Phosphatase (ALP)}

This enzyme requires the use of colorimetric method. This procedure is an enhanced standard technique recommended by the Deutsche Gesellschaft für Klinische Chemie und Laboratoriumsmedizin e.V. (DGKL). The assay was read at a wavelength of $\mathrm{Hg} 405 \mathrm{~nm} .0 .05 \mathrm{ml}$ of the sample was pipetted against $3 \mathrm{ml}$ of the reagent in the micro plate wells. It was mixed and read, the initial absorbance was recorded and stop watch started. It was read again after 1, 2 and $3 \mathrm{~min}$, all samples collected were stored at $4^{\circ} \mathrm{C}$ and tested within $72 \mathrm{hrs}$ of collection.

\subsection{Data Analysis}

Statistical Package for the Social Sciences (SPSS IBM® version 23) and GraphPad Prism (Version 8.0.2) were used in analysing the data. Descriptive statistics were performed for continuous data and represented as mean (S.D) while frequencies (\%) were used to express categorical data. Z-test was used to determine mean difference while Fisher's Chi-square analysis was used to determine trends and association. Confidence level was set at 95\% and P-value less than 0.05 was considered significant.

\section{RESULTS}

The mean values of the hepatic enzyme markers presented in Table 1 showed that the mean(S.D) AST (27.65 $\pm 17.93 \mathrm{U} / \mathrm{L})$ and ALP (135.13 \pm 10.87 $U / L)$ values for males were higher than the female values $(A S T=27.25 \pm 18.93 \mathrm{U} / \mathrm{L}$ and ALP $(132.65 \pm 9.96 \mathrm{U} / \mathrm{L})$, whereas females (34.66 $\pm 22.29 \mathrm{U} / \mathrm{L})$ had higher ALT values than males $(33.75 \pm 18.14 \mathrm{U} / \mathrm{L})$. However, the t-test of mean differences presented in Fig. 2 did not reveal any significantly differences $(P>0.05)$ (Fig. 2).

The values obtained were categorized; within [normal] and outside normal limit [abnormal] and the Chi-square analysis of sex association were represented in Table 2. The result for AST and ALT showed that males patients (AST $=34$; $73.9 \%$ and $\mathrm{ALT}=31 ; 67.4 \%$ ) were observed to have more normal values than females (AST = $55 ; 66.3 \%$ and $\mathrm{ALT}=53 ; 63.9 \%$ ). But slightly lower normal ALP values were observed for males $(8 ; 17.4)$ when compared to females (15; 18.10). The differences in AST $\left(x^{2}=0.809\right.$; $p=0.368), \operatorname{ALT}\left(x^{2}=0.163 ; p=0.686\right)$, and ALP $\left(x^{2}=0.009 ; \quad p=0.923\right)$ were not statistically significant.

Among the patients, $17.8 \%(6 ; 13.0 \%$ males and $17 ; 20.5 \%$ female) were normal, while no patient (male or female) had abnormal AST levels. 3; $2.3 \%$ of the patents had abnormal ALT levels. $59 ; 45.7 \%$ of the patients (males: 25 [54.3\%] and females: 34 [41.0\%]) had cholestatic abnormality (higher than normal ALP levels). For hepatocellular abnormality, $8.5 \% \quad(5 ; \quad 10.9 \%$ males and $6 ; 7.2 \%$ females) were observed for this group, while for mixed abnormality (AST/ALT/ALP), $18.6 \% \quad(6 ; 13.0 \%$ of males and $18 ; 21.7 \%$ of females) fell into this class (Table 3).

Table 1. The mean, standard deviation of the liver enzymes of HIV patients on HAART

\begin{tabular}{clc}
\hline & \multicolumn{2}{c}{ Mean \pm S.D } \\
\cline { 2 - 3 } & Male $(\mathbf{n = 4 6 )}$ & Female $(\mathbf{n = 8 3})$ \\
\hline AST $(\mathrm{U} / \mathrm{L})$ & $27.65 \pm 17.93$ & $27.25 \pm 18.93$ \\
ALT $(\mathrm{U} / \mathrm{L})$ & $33.75 \pm 18.14$ & $34.66 \pm 22.29$ \\
ALP $(\mathrm{U} / \mathrm{L})$ & $135.13 \pm 10.87$ & $132.65 \pm 9.96$ \\
\hline \multicolumn{2}{c}{ Note: Aspartate Aminotransferase [AST], Alanine } \\
\multicolumn{2}{c}{ Transaminase [ALT], Alkaline Phosphatase [ALP] }
\end{tabular}




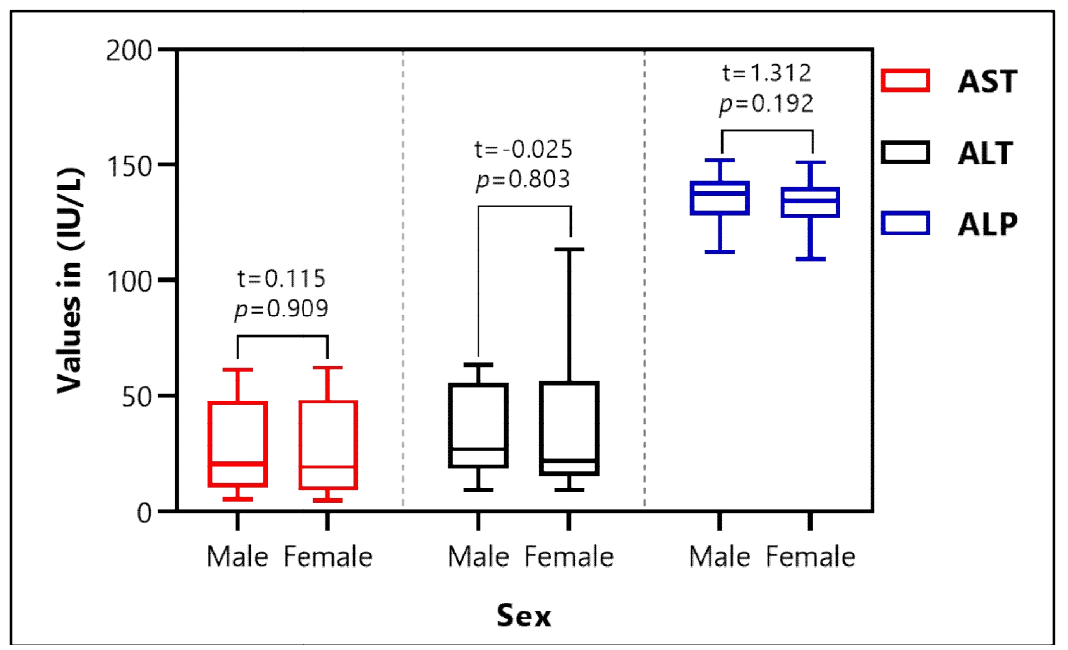

Fig. 2. Comparison of the mean AST, ALT and ALP levels in males and female

Table 2. Liver enzyme characteristics and test of sex-associated distributional test differences

\begin{tabular}{llllll}
\hline & & Normal (\%) & Abnormal (\%) & Chi-sq. $\left(X^{2}\right)$ & P-value \\
\hline AST & Male & $34(73.9)$ & $12(26.1)$ & 0.809 & 0.368 \\
& Female & $55(66.3)$ & $28(33.7)$ & & \\
& Total & $89(69.0)$ & $40(31.0)$ & & 0.686 \\
\hline ALT & Male & $31(67.4)$ & $15(32.6)$ & 0.163 & \\
& Female & $53(63.9)$ & $30(36.1)$ & & 0.923 \\
& Total & $84(65.1)$ & $45(34.9)$ & & \\
\hline ALP & Male & $8(17.4)$ & $38(82.60)$ & 0.009 & \\
& Female & $15(18.10)$ & $68(81.90$ & & \\
& Total & $23(17.8)$ & $106(82.2)$ & \\
\hline \multicolumn{5}{r}{ Note: Aspartate Aminotransferase [AST], Alanine Transaminase [ALT], Alkaline Phosphatase [ALP] } \\
& \multicolumn{7}{c}{ Normal values: ALT (7 to 55 U/L), AST (8 to 48 U/L), and ALP (40 to 129 U/L) }
\end{tabular}

Table 3. Liver enzyme characteristics and associated coexistence of abnormalities

\begin{tabular}{|c|c|c|c|}
\hline \multirow{2}{*}{ Hepatological condition } & \multicolumn{2}{|c|}{ Sex } & \multirow{2}{*}{ Total (\%) } \\
\hline & Male (\%) & Female (\%) & \\
\hline Normal & $6(13.0)$ & $17(20.5)$ & $23(17.8)$ \\
\hline AST & - & - & - \\
\hline ALT & $1(2.2)$ & $2(2.4)$ & $3(2.3)$ \\
\hline ALP & $25(54.3)$ & $34(41.0)$ & $59(45.7)$ \\
\hline AST/ALT & $5(10.9)$ & $6(7.2)$ & $11(8.5)$ \\
\hline AST/ALP & - & $2(2.4)$ & $2(1.6)$ \\
\hline ALT/ALP & $3(6.5)$ & $4(4.8)$ & $7(5.4)$ \\
\hline AST/ALT/ALP & $6(13.0)$ & $18(21.7)$ & $24(18.6)$ \\
\hline
\end{tabular}

\section{DISCUSSION}

Since the alarming rise in HAART-induced hepatotoxicity, prevention and management of ART-related toxicity has emerged as a major issue for HIVIAIDS treatment and care. In this study, the mean AST and ALT of male and female HIV patients were within the normal range, while the ALP values were way above upper limit of $129 \mathrm{U} / \mathrm{L}$ for normal values [6]; however, more females had ALT and AST values that were above the normal upper limit reported by Ruhl and Everhart, 2012 [16]. The finding in this study agrees with previous observations; that 
up to $14-20 \%$ and recently $60 \%$ of HIV patients will have elevated enzymes levels upon commencement of ART [7,8,21,22].

The findings in this study do not agrees with the reports of more independent association with mild increase in ALT and AST values; [23] as independent ALT and AST abnormality were less common when compared to both abnormalities (ALT/AST). On the other hand, ALP as an independent abnormality was the most observed; accounting for more than $40 \%$. Predominant abnormal ALP levels in HIV patients without hepatitis co-infection has been reported [23,24]. In the study by Maida, [24] among 17 patients with increased liver enzymes, ALP was elevated in 16. Sterling et al. [23] also found that evaluated ALP was more common than AST or ALT. It is also important to note that mixed (hepatocellular + cholestatic abnormality) was commoner among females while independently, hepatocellular and cholestatic abnormality was more observed in males.

There are several possible mechanisms that are specific to HIV medications capable of causing liver enzyme elevations; however, most HAART contain Pls which has been associated with the development of insulin resistance (IR) and dyslipidaemia, both risk factors for steatosis [2529]. Additionally, BMI $>30$ and Diabetes Mellitus (DM) have been associated with increased liver enzymes in HIV patients on HARRT [23].

The findings in this study do not categorically exclude sex influence in hepatic enzyme abnormalities in HIV-infected patients (without hepatitis co-infection), because the mechanism of action of HIV drugs in inducing hepatotoxicity may be significantly influenced by hormones (which vary with sex), and other clinical conditions such as BMI, diet type and DM, which are not directly associated the HIV infection.

\section{CONCLUSION}

Generally, among HIV-infected patients on HAART in UPTH, cholestatic abnormalities were observed in more than $80 \%$ of the patients as opposed to hepatocellular abnormalities, which were less than $35 \%$. More females were associated with mixed abnormality when compared to males with independent (ALT/AST) abnormality. Any observed sex-associated difference could be associated with a series of unidentified mechanisms of action of HAART. This study, therefore, suggests the need for a randomised case-control study to highlight the extent of deviation from normal values.

Ultimately, there is a need for hospitals to design and implement timely intervention and management strategies; to reduce the rate of drug-induced liver damage in HIV-infected patients. Therefore, it is mandatory for policymakers to develop better and newer management strategies; to reduce the burden associated with drug toxicity in HIV-infected patients.

\section{CONSENT AND ETHICAL APPROVAL}

Ethical approval with reference number UPH/CEREMAD/REC/18 was obtained from the Research Ethics Committee of the University of Port before commencement of the research. The study was conducted in line with the Declaration of Helsinki, [30] and all other relevant statutory regulations were observed. Informed consents were obtained from all participating patients.

\section{COMPETING INTERESTS}

Authors have declared that no competing interests exist.

\section{REFERENCES}

1. Palella FJJ, Delaney KM, Moorman AC, Loveless MO, Fuhrer J, Satten GA. Declining morbidity and mortality among patients with advanced human immunodeficiency virus infection. HIV Outpatient Study Investigators. N Eng J Med. 1998;338:853-860.

2. Young B. Review: Mixing new cocktails: Drug interactions in antiretroviral regimens. AIDS Patient Care STDS. 2005;19:286297.

3. Ngala RA, Opoku D, Asare G. Effects of HIV infection and highly active antiretroviral therapy (HAART) on the Liver of HIV Patients. Trends in Medical Research. 2015;10:1-11.

4. Wambani JR, Ogola PE, Arika WM, Rachuonyo HO, Kemboi NG, Lihana R, and Burugu MW. Anti-retroviral drug hepatotoxicity and risk factors in HIV patients with or without hepatitis $B$ and $C$ : A Review. Journal of Infectious Diseases and Therapeutics. 2016;3:258.

5. Neukam K, Mira JA, Collado A, RiveroJuárez A, Monje-Agudo $P$, Ruiz-Morales J, ... HEPAVIR SEG-HEP-2007 study group of the sociedad andaluza de 
enfermedades infecciosas (SAEI). Liver Toxicity of Current Antiretroviral Regimens in HIV-Infected Patients with Chronic Viral Hepatitis in a Real-Life Setting: The HEPAVIR SEG-HEP Cohort. PLoS One. 2016;11(2):e0148104.

6. Mayo Foundation for Medical Education and Research (MFMER). Liver function tests. Mayo Clinic; 2019.

Available:https://www.mayoclinic.org/testsprocedures/liver-function-tests/about/pac20394595

[Accessed on 8 August, 2019]

7. Rodriguez-Rosado R, Garcia-Samaniego J, Soriano V. Hepatotoxicity after introduction of highly active antiretroviral therapy. AIDS. 1998;12(10):1256.

8. The Center for AIDS Information \& Advocacy (CFA). High liver enzymes signal serious disease in HIV-positive individuals without hepatitis; 2015.

Available:https://www.thebodypro.com larticle/high-liver-enzymes-signal-seriousdisease-in-hiv-p

[Accessed on 8 August, 2019]

9. Cooper CL, Parbhakar MA, Angel JB. Hepatotoxicity associated with antiretroviral therapy containing dual versus single protease inhibitors in individuals coinfected with hepatitis $\mathrm{C}$ virus and human immunodeficiency virus. Clinical infectious diseases: An official publication of the Infectious Diseases Society of America. 2002;34(9):1259-1263.

10. Heil EL, Townsend ML, Shipp K, Clarke A, Johnson MD. Incidence of severe hepatotoxicity related to antiretroviral therapy in HIV/HCV coinfected patients. AIDS research and treatment. 2010; 856542.

11. Kalyesubula $R$, Kagimu $M$, Opio $K C$, Kiguba R, Semitala CF, Schlech WF, et al. Hepatotoxicity from first line antiretroviral therapy: An experience from a resource limited setting. African Health Sciences. 2011;11(1):16-23.

12. Ungo JR, Jones D, Ashkin D, Hollender ES, Bernstein D, Albanese AP, et al. Antituberculosis drug-induced hepatotoxicity. The role of hepatitis $\mathrm{C}$ virus and the human immunodeficiency virus. American Journal of Respiratory and Critical Care Medicine. 1998;157(6 Pt1): 1871-1876.

13. Mugusi S, Ngaimisi E, Janabi M, Minzi O, Bakari M, Riedel KD, et al. Liver enzyme abnormalities and associated risk factors in
HIV patients on efavirenz-based HAART with or without tuberculosis co-infection in Tanzania. PloS One. 2012;7(7):e40180.

14. Segamwenge IL, Bernard MK. Acute liver failure among patients on efavirenz-based antiretroviral therapy. Case Reports in Hepatology. 2018;Article ID 1270716:5.

15. Murali AR. Liver test interpretation Approach to the patient with liver disease: A guide to commonly used liver tests. Clivland Clinics (Centre for Continuing Education); 2017.

Available:

http://www.clevelandclinicmeded.com/medi calpubs/diseasemanagement/hepatology/g uide-to-common-liver-tests/\#bib1

[Accessed on 8 August, 2019]

16. Ruhl CE, Everhart JE. Upper limits of normal for alanine aminotransferase activity in the United States population. Hepatology. 2012;55:447-454.

17. Wu L, He Y, Jiang B, et al. Gender difference in the association between aminotransferase levels and hypertension in a Chinese elderly population. Medicine (Baltimore). 2017;96(21):e6996.

18. Anyanwu CF, Obianime AW, Siminialayi $\mathrm{IM}$, Aigbogun (Jr.) EO. Evaluating the effects of Moringa oleifera on atherogenic lipoprotein indices of HIV infected Nigerian adults on tenofovir based antiretroviral regimen. International Journal of Clinical and Experimental Pharmacology. 2019; 8(6):1312-1319

19. Koehler EM, Schouten JN, Hansen BE, van Rooij FJ, Hofman $A$, Stricker $B H$, Janssen HL. Prevalence and risk factors of non-alcoholic fatty liver disease in the elderly: Results from the Rotterdam study. J Hepatol. 2012;57(6):1305-1311.

20. Kim IH, Kisseleva T, Brenner DA. Aging and liver disease. Curr Opin Gastroenterol. 2015;31(3):184-191.

21. Sabin CA. Pitfalls of assessing hepatotoxicity in trials and observational cohorts. Clin Infect Dis. 2004;38(Suppl 2):S56S64.

22. Sulkowski MS, Mehta SH, Chaisson RE, Thomas DL, Moore RD. Hepatotoxicity associated with protease inhibitor-based antiretroviral regimens with or without concurrent ritonavir. AIDS. 2004;18(17): 2277-2284.

23. Sterling RK, Chiu S, Snider K, Nixon D. The prevalence and risk factors for abnormal liver enzymes in HIV-positive patients without hepatitis $\mathrm{B}$ or $\mathrm{C}$ 
coinfections. Dig Dis Sci. 2008;53(5): $1375-1382$.

24. Maida I, Núñez M, Ríos MJ, MartínCarbonero L, Sotgiu G, Toro C, Rivas P, et al. Severe liver disease associated with prolonged exposure to antiretroviral drugs. J Acquir Immune Defic Syndr. 2006;42(2): 177-182.

25. Carr A, Samaras K, Thorisdottir A, Kaufmann GR, et al. Diagnosis, prediction, and natural course of HIV-1 proteaseinhibitor-associated lipodystrophy, hyperlipidemia and diabetes mellitus: a cohort study. The Lancet. 1999;353:2093-2099.

26. Hui DY. Effects of protease inhibitor therapy on lipid metabolism. Progress in Lipid Research. 2003;42:81-92.
27. Mulligan K, Grundfeld C, Tai VW, Algren $\mathrm{H}$, et al. Hyperlipidemia and insulin rsistance are induced by protease inhibitors independent of changes in body composition in patients with HIV infection. JAIDS. 2000;23:35-43.

28. Nolan D, Mallal S. Getting to the HAART of insulin resistance. AIDS. 2001;15(15): 2037-2041.

29. Stein $\mathrm{JH}$. Dyslipidemia in the era of HIV protease inhibitors. Progress in Cardiovascular Diseases. 2003;45:293304.

30. Snežana B. The declaration of Helsinki: The cornerstone of research ethics. Archive of Oncology. 2001;9(3):179184.

(c) 2020 Anyanwu et al.; This is an Open Access article distributed under the terms of the Creative Commons Attribution License (http://creativecommons.org/licenses/by/4.0), which permits unrestricted use, distribution, and reproduction in any medium, provided the original work is properly cited.

Peer-review history:

The peer review history for this paper can be accessed here: http://www.sdiarticle4.com/review-history/51211 